\title{
A 3-Stage Treatment System For Domestic Wastewater: Part I. Development
}

\author{
Oon, Y. W. ${ }^{1}$, Law, P. L. ${ }^{2}$, Ting, S. N. ${ }^{3}$, Tang, F. E. ${ }^{4}$
}

\begin{abstract}
This study presents the development of a micro-scaled 3-stage wastewater treatment system applicable to small volume domestic effluents. The primary components of the system include 1) Spiral-Framed Human Hair-Based Filter, 2) Plastic Medium Mixed Flow Biotower, and 3) Pistia Stratiotes-Based Free Surface Water Wetland System. The first stage Spiral-Framed Human Hair-Based Filter consists of an oil and grease removal apparatus filled with human hair blocks and operated in a spiral plane aimed at removing emulsified oils from wastewater. The process is followed by a second stage Plastic Medium Mixed Flow Biotower filled with perforated cylindrical plastic tubes in horizontal and vertical arrangements to provide alternate vertical and cross flows for removal of suspended solids, ammoniacal-nitrogen, and biochemical oxygen demand. The effluent would then be channelled to the free surface water wetland system (third stage) filled with Pistia Stratiotes (water lettuce) for removal of nutrients such as nitrogen, phosphorus, and potassium from wastewater. From this study, it was found that Human Hair-Based Filter could remove 73.54\% emulsified oils from wastewater, while the combined removal efficiencies of Plastic Medium Mixed Flow Biotower and Free Surface Water wetland system operated in series recorded 59.2\% biochemical oxygen demand, 87.9\% ammoniacalnitrogen, $\mathbf{9 0 . 6 \%}$ nitrogen, $54.9 \%$ phosphorous, $68.5 \%$ potassium, and $59.0 \%$ turbidity.
\end{abstract}

Keywords: Emulsified oils, human hair, spiral plane, biotower, free surface water wetland, Pistia Stratiotes

\section{INTRODUCTION}

B

ASED on statistical data for years 2002-2004, the oil and grease levels in Malaysian marine waters had exceeded $49.1 \%$

of the Interim Marine Water Quality Standards (IMWQS) if compared to the previous 10 years [9]. Conventional methods used in treating oil pollution may include chemical dispersants, mechanical collection or natural removal. However, these methods are restricted mainly by time and economic factors [24], [27]. This has led to a rapid blooming of research and development in various removal systems. The ability of human hair in removing oil and grease $(O \& G)$ from water has been proven by Tamar J.F. who experimentally discovered that significant amount of oil droplets could be adsorbed onto the human hair [31]. Oil and grease removal by using human hair is an inspiration of Philip McCrory in 1989 who used human hair bundles to remove oil slick from water. This finding was verified by The National Aeronautic and Space Administration's (NASA's) Marshall Center in Huntsville, Alabama (USA) [7] that had sparked off various research projects in schools and research institutions. Human hair was believed to be a sustainable source for wastewater treatment and as an unusual adsorbent material for oil spill cleanups, especially for heavy toxin metal removal [18]. Depending upon the concentrations of oil contamination in water, the adsorption capacities of hair varied from 1 to $27 \mathrm{mg}$ of metal per gram of hair [18]. A study showed relatively fast uptake of cadmium and lead by Cattail Leaves suggested that a continuous process was viable. The results were similar in the case of hair and mercury. However, the study by [3] did not support the hypothesis that animal furs or hairs had better adsorption ability than polypropylene, but it did prove the ability of animal hairs in adsorbing oil volume to a certain level [3]. [33] looked into oil adsorption ability of sheep wool, polypropylene and hay, and the tests had proven the ability of animal hair in oil-picking characteristics [33]. It was shown that cotton had an average adsorptive capacity of approximately $420 \%$ of its own weight and human hair adsorbed $93 \%$ of its own weight [4].

The O\&G removal unit developed in this research (i.e., Spiral-Framed Human Hair-Based Filter (HBF)) was designed based on the Logarithmic Spiral under the Theory of Archimedes's Spiral and the rotation angle versus radius of the spiral arc [10], [11]. It operates in a spiral plane by taking advantage the surface area of contacts (between the human air and oil droplets) reaction duration (figure 1) [1], [13]. A spiral movement of flow enables the wastewater to flow in a spiral manner with decreasing curvature in the system becomes one of the unique characteristics of the flow pattern. The flow movement has a decelerating horizontal velocity, $v_{h}$ with increasing distance from the inlet as a result of continual increase in surface area coupled with spiral angular movement [8], [25], [30].

\footnotetext{
${ }^{1}$ Oon, Y. W., Student of Civil Engineering Department, Universiti Malaysia Sarawak (e-mail: oonyinwee@gmail.com)

${ }^{2}$ Law, P. L., Professor of Civil Engineering Department, Universiti Malaysia Sarawak (e-mail: puonglaw@ feng.unimas.my)

${ }^{3}$ Ting, S. N., Senior Lecturer of Civil Engineering Department, Universiti Malaysia Sarawak (e-mail: snting@ feng.unimas.my

${ }^{4}$ Tang, F. E., Senior Lecturer of Civil \& Construction Engineering Department, Curtin University of Technology (Sarawak Campus)(email: tang.fu.ee@curtin.edu.my)
} 


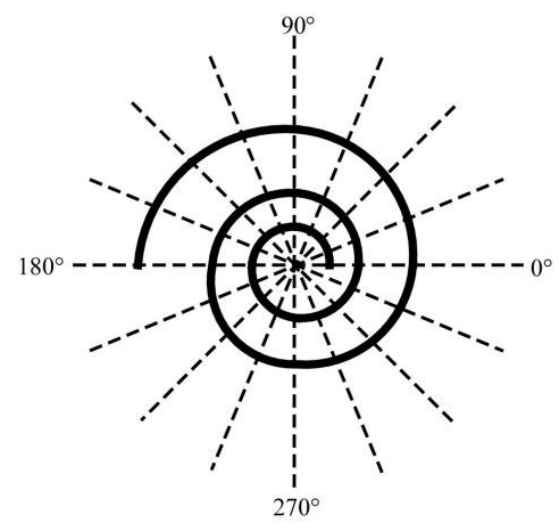

Figure 1. Flow Pattern of HBF in Archimedean Spiral Curve.

A reduction in horizontal velocity, $v_{h}$ enhances the adsorption rate of oil droplets on human hair tissues. At the same time, the presence of human hair blocks at both sides of the flow path promotes optimum oil-liquid separation by principles of McCrory's findings that hair fabrics had excellent ability in oil slick adsorption [20], [28]. The spiral movement also would maximize the frequency of collision of oil droplets onto the hair block surfaces, thus encouraging oil droplet adsorption to take place while minimizing clogging by providing sufficient gap in between both the hair block sides along the movement path (spacing of the gap is proportional to spiral path) [13]. The tiny O\&G droplets would collide onto human hair as they move along the spiral path of the system. The primary design features of HBF of the system are included in the following paragraphs.

1) Installation of hair blocks at both sides of the flow path. Hair blocks successively installed along both sides of the flow path promote optimum adsorption efficiency when the oil drops pass through the system. Collisions between the hair blocks and oil drops would significantly be raised when the contact surface area is increased, and thus more oil drops could be trapped.

2) Installation of hair blocks in spiral plane. Movement in spiral plane involves rapid and continual turning and reflection of flow. This promotes more adsorption occurrences between hair blocks and oil drops.

The aerobic wastewater treatment system utilizes microorganisms for removal of suspended solids and dissolved organic matters from wastewaters [14], [16], [32]. Thus, plant such as water hyacinth, with long and congested roots would have good adsorption power to the organic pollutants. As the influent moves along the tank, organic matter is biodegraded either aerobically or anaerobically. Nutrients are eliminated through a variety of biological, physical and chemical processes with a certain degree of water being transpired [6], [12], [21].The nutrients could be assimilated by Pistia Stratiotes growing in the free surface water (FSW) wetland [6]. Previously water hyacinth had shown to produce yields amounting to approximately $30.1 \mathrm{~g} / \mathrm{m}^{2}$ per day (dry matter), but their overall value was low because their mass was offset by its low nutrient value, low digestibility, high harvesting expense, and water loss by evaporation [2], [29].

Traditional biotower or trickling filter consists of a bed of a highly permeable medium to which microorganisms are attached and through which wastewater is percolated or trickled [16]. The filter media usually consist of either rock or a variety of plastic packing materials. Rock filter beds are usually circular, and wastewaters are distributed over the top of the bed by a rotary distributor [32]. As wastewater trickles downwards over the slime layer, organic matters and dissolved oxygen are extracted, metabolic end products such as carbon dioxide are released, and organic content would decrease to the point where microorganisms in the lower zone are in a state of starvation. Thus, a majority of biochemical oxygen demand is extracted from the wastewater after passing through the filter media [14], [32].

These bacterial populations would carry out nitrification process sequentially and oxidize ammonium growing on the slime layer to nitrate with intermediate formation of nitrite carried out by nitrosomanas and nitrobacter. The two steps in nitrification process and their equations are as follows [32]:

i) Ammonia is oxidized to nitrite $\left(\mathrm{NO}_{2}^{-}\right)$by Nitrosomanas bacteria.

$$
2 \mathrm{NH}_{4}^{+}+3 \mathrm{O}_{2} \rightarrow 2 \mathrm{NO}_{2}^{-}+4 \mathrm{H}^{+}+2 \mathrm{H}_{2} \mathrm{O}
$$

ii) The nitrite is converted to nitrate $\left(\mathrm{NO}_{3}{ }^{-}\right)$by Nitrobacter bacteria.

$$
2 \mathrm{NO}_{2}^{-}+\mathrm{O}_{2} \rightarrow 2 \mathrm{NO}_{3}^{-}
$$

In recent times, rock biotowers are continuously being upgraded and rehabilitated with plastic sheet media and synthetic media to replace the use of stone. As compared to rock, plastic sheet media are 2 to 3 times higher in specific surface area, providing proportionally more area for biomass attachment [34], [35]. Thus, void volume that improves ventilation and hydraulic loading capacity would be substantially increased. At present, primary types of plastic flow media widely used include cross flow media, vertical flow media and mixed flow media. In cross-flow media design, down-flowing liquid is splitted at each cross point creating more redistribution points, and its major drawbacks are its inferior bio-solids flushing action and biomass fouling problem [23]. Vertical flow media has vertical channels with cross flow at the module interface by making use of its limited inner surface area of the channels that results in low specific surface area available for biomass attachment and low organic loading. Commercially available mixed media takes advantage of its uniformity in distribution 
UNIMAS e-Journal of Civil Engineering, Vol. 4: Issue 1/April 2013

of wastewater over the surface of the filter by alternating cross-flow and vertical flow media layers [23]. Additionally, mixed media filter reduces excessive biomass build up of shearing materials from vertical layers. This medium type and 


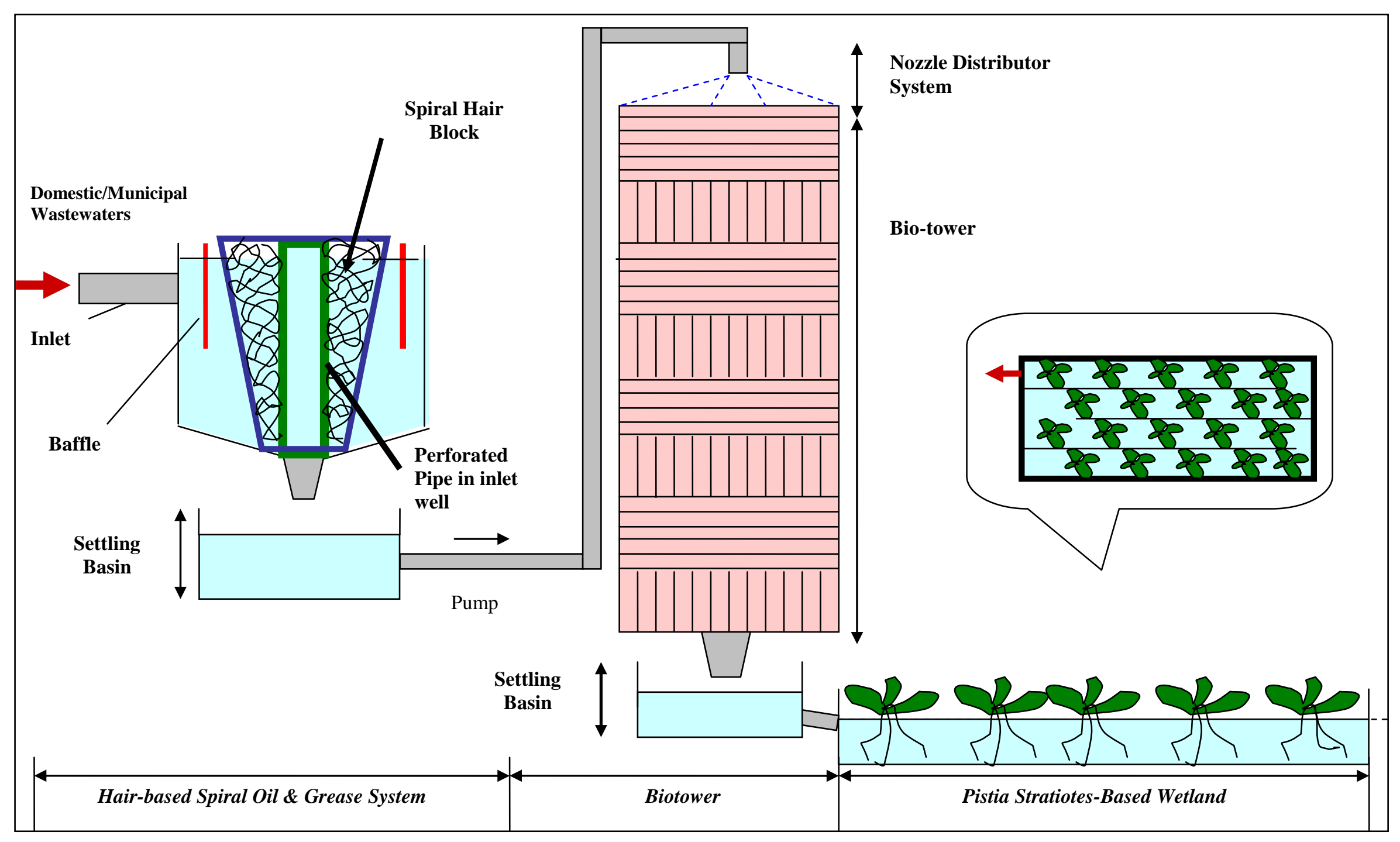

Figure 2. Schematic Flow Process of the 3-Stage Treatment System. 
arrangement could provide approximately $16 \%$ more surface area per volume from the recommended plastic crossflow media of $15.84 \mathrm{~m}^{2} / \mathrm{m}^{3}$ [5].

Pistia Stratiotes grow profusely in the tropics and the use of aquatic plants as one of the functional units in municipal wastewater treatment has increasingly proven its potential [6], [21]. For instance, duckweed-based wastewater treatment has been implemented by the city of San Diego, United State of America to produce a treated effluent attaining quality standards that would be expected from advanced secondary treatment processes [6]. Water Lettuce could potentially be used in both tertiary treatment systems for the removal of nutrients, and in integrated secondary and tertiary treatment systems for removal of both organics and nutrients [6], [23]. The Pistia Stratiotesbased wetland is a free surface water (FSW) wetland system typically formed by shallow channels or basins where the water surface is open to the atmosphere and a suitable medium exists to support the growth of emergent or submerged aquatic plants [23], [32]. Wastewater treatment takes place as the hyacinth assimilate nutrients from the effluents [6]. Recently, two floating aquatic "Macrophyte" plants have been used in wastewater treatment including Eichhornia Crassipes (a type of water lettuce) and Lemnacea Spirodella (duckweed) [5]. As the influents move along the system, organics are biodegraded either aerobically or anaerobically. Nutrients are reduced through a variety of biological, physical and chemical processes [6], [21]. It is believed that two major mechanisms for ammonia reduction in hyacinth systems are bacterial nitrification and plant uptake [15].

Similar research had been carried out by [17] with two low-cost bamboo biotowers and a wastewater pond system constructed and applied for two years for a secondary treatment of municipal wastewater [17]. The results showed that the system had a capability of removing organic matter, nitrate and phosphate from waterway.

\section{MATERIALS AND METHODS}

$\mathrm{T}$ HIS research involves the development and field tests of a 3-stage micro-scaled treatment system for domestic wastewaters of small volume, loaded with physically emulsified and free oils (O\&G), suspended solids (SS), biochemical oxygen demand (BOD), ammoniacal-nitrogen $\left(\mathrm{NH}_{3}-\mathrm{N}\right)$, nitrogen $(\mathrm{N})$, phosphorus $(\mathrm{P})$ and potassium $(\mathrm{K})$. As illustrated in figure 2, the system consists of 1) spiral-framed human hair-based filter, 2) a biotower, and 3) Pistia Stratiotes-based FSW wetland system operating in series.

\section{Stage 1: Spiral-Framed Human Hair-Based Filter (HBF)}

The HBF operates in spiral plane movement that enables the horizontal velocity, $v_{h}$ to decelerate along the distance from the inlet to the perimeter baffle zone, as a result of continual increase in surface area [20], [25], [26]. As the horizontal velocity, $v_{h}$ decreases, the adsorption rate of most oil droplets onto human hair fabrics would increase. The usage of double-sided hair blocks along the flow path would enhance hair fabrics' ability to adsorb O\&G. An optimum amount of oil droplets would collide onto the hair block surfaces where adsorption takes place and the spacing between the hair block would minimize the occurrence of clogging along the movement path (figure. 3).

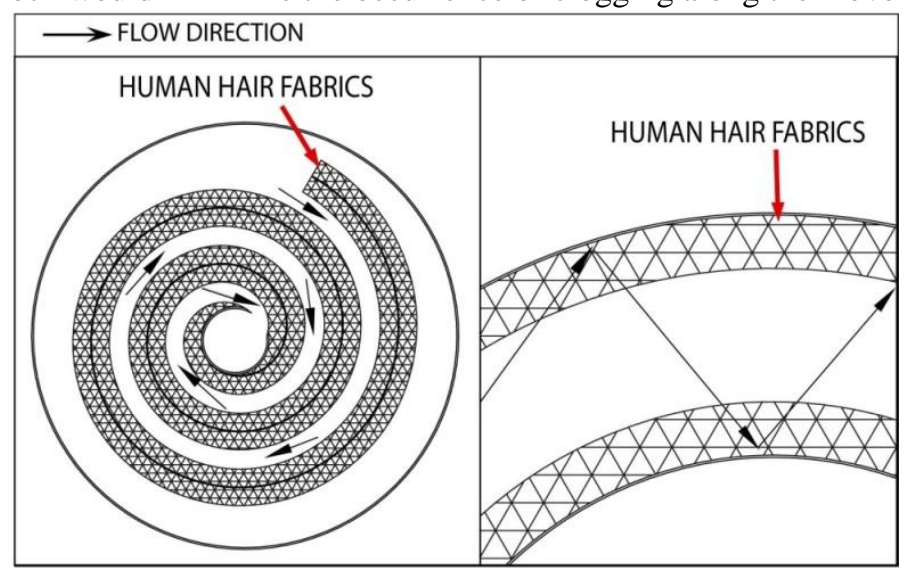

Figure 3. Spiral Plan Flow Pattern in HBF.

The hypothetical operational principles of HBF would be pivoted upon the arrangement or orientation of the hair blocks' thickness, gap spacing and the spiral angles of the movement path. However, other factors such as influent concentration, flowrate, viscosity and specific gravity, detention time, and temperature also could play an important role in removal efficiency of $\mathrm{O} \& \mathrm{G}$ from wastewater.

The features of the recently developed HBF (figure 4) include a 750mm in diameter and 460mm high circular basin, that take advantage of continual reduction in horizontal velocity as surface area increases. Other systems employ rectangular tanks whereby the horizontal velocity, $v_{h}$ is constant throughout [1], [13]. The HBF is a center-feed 
upflow system possessing a $150 \mathrm{~mm}$ diameter inlet well. The $250 \mathrm{~mm}$ thick hair blocks zone, which was formed by human hair in caging wire mesh attached onto both sides of a spiral-planed aluminum plate with a spacing of $110 \mathrm{~mm}$ between them, and the spacing decreases proportionally along the moving path. The hair blocks were designed with 4:3:4 ratio (figure 5), i.e. both sides of the plates were attached to $40 \mathrm{~mm}$ thick of hair blocks with $30 \mathrm{~mm}$ of clear space in between the hair blocks. Hypothetically, it was considered that the proposed 40mm of thickness is capable of removing the oil slick and the $30 \mathrm{~mm}$ spacing (for wastewater flow) was sufficient in directing the flow without clogging.

Generally, oil molecules are trapped by hair surface structure and when the capture is large enough, or the surface entrapment is fully attached, the hairs will act in bundles to adsorb the oil molecules. More molecules will be trapped in between the intersection zone of individual hair due to molecular coalescence (figure 6). The tendency of flow in rotating angle forces the molecules to collide onto the intersection zones. The thick hair blocks (bundles) along the path are dense enough to create an entrapment force to retain the coalesced oil molecules (figure 7). The frictional force in entrapment created is relevant or correlated to the thickness and rotation angle of the hair blocks, but there is always an optimum limit where excessive thickness may not enhance the entrapment. Due to this reason, this component of the system was designed to a ratio of 4:3:4 cm of hair block to clear the path along the initial $11 \mathrm{~cm}$ partition gap (figure 5).

The outlet baffle, which was a $50 \mathrm{~mm}$ periphery overflow outlet weir channel to provide uniform flow as outlet launder which directs the effluent out of the apparatus. The effluents from the HBF are then collected prior to discharge into the next stage of the system, which is the biotower (MFB) designed to remove organic matters such as A-N, N, BOD and SS from wastewater.
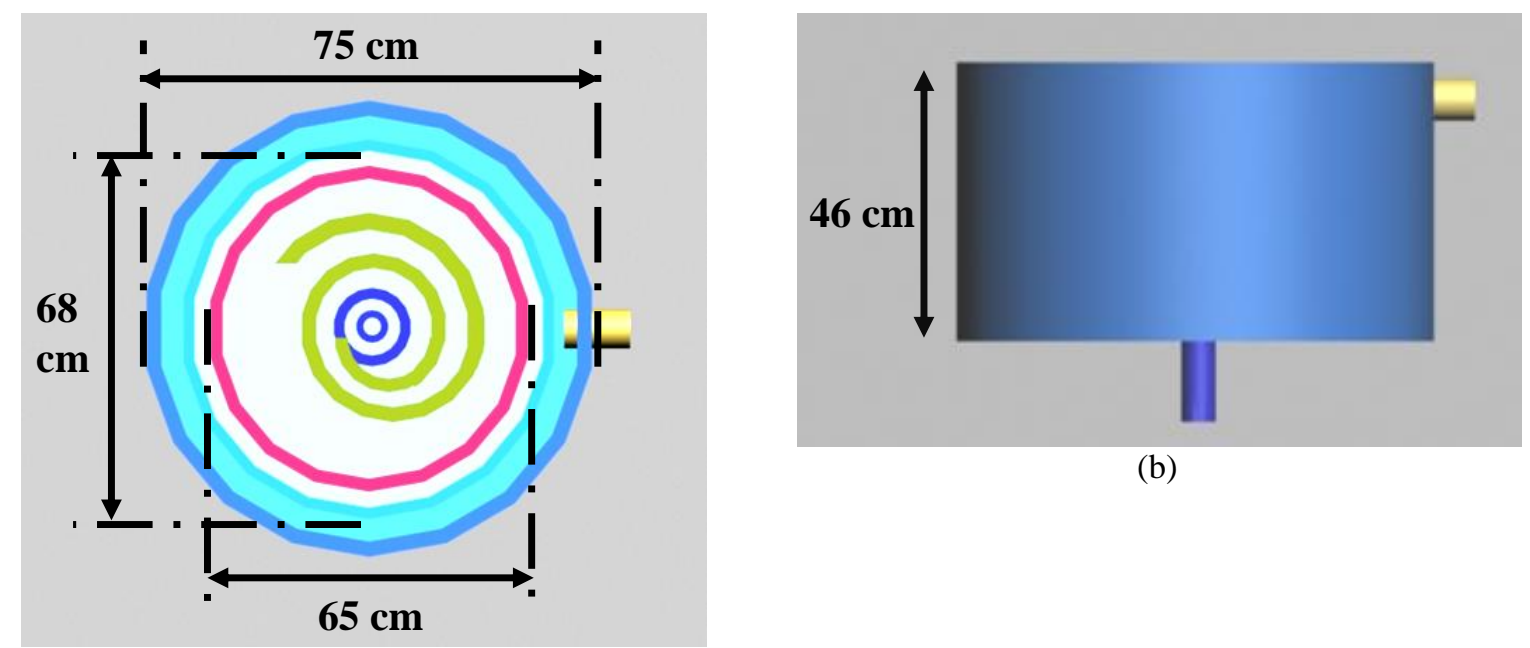

(b)

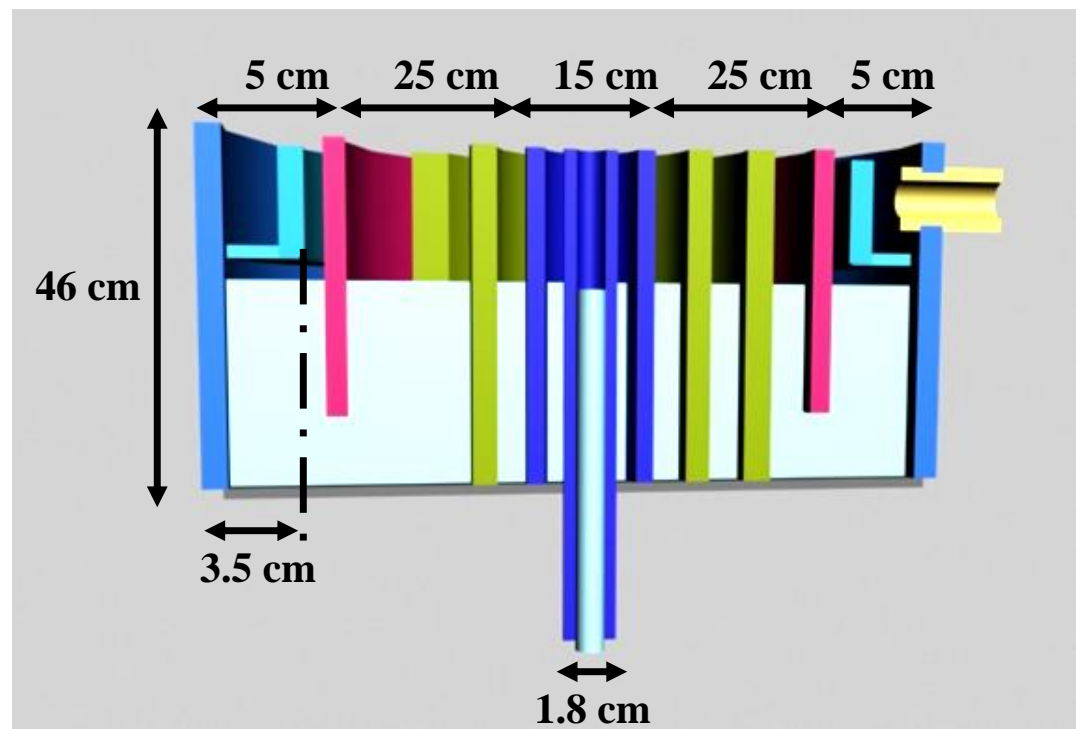

(c) 


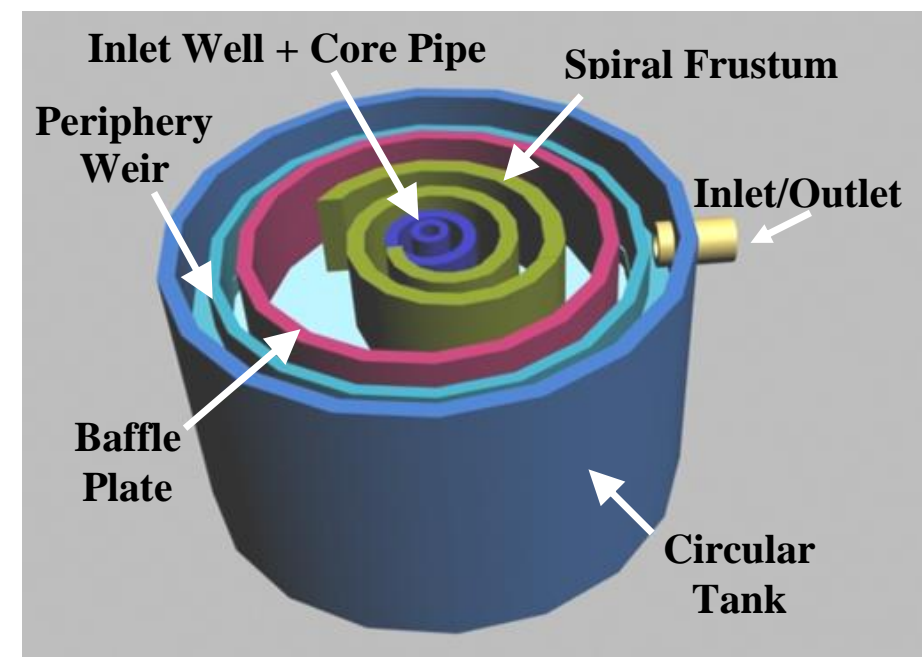

(d)

Figure 4. Spiral-Framed Human Hair-Based Filter: a) Top, b) Side, c) Cross-Section, and d) Perspective Views

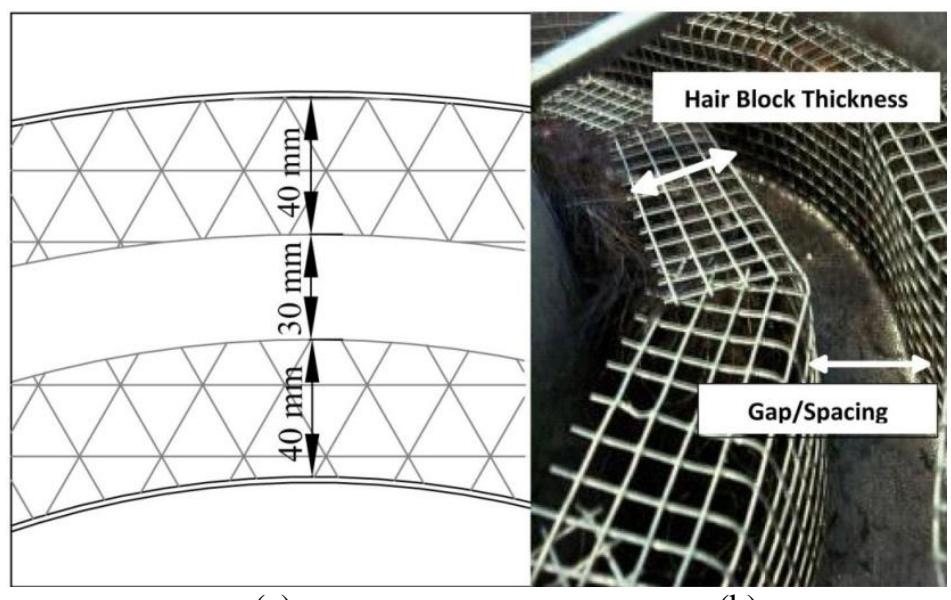

(a)

(b)

Figure 5. Partition Dimensions in Spiral Frustum, a) Plan view; b) Perspective view

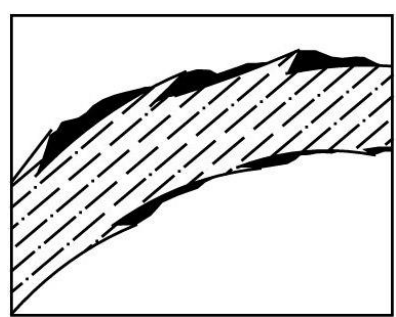

Figure 6. Oil Molecules Adsorption on Individual Hair

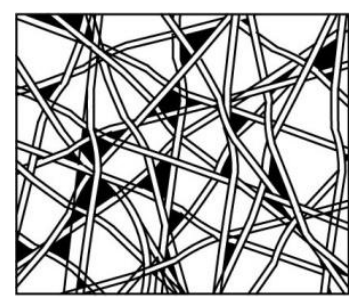

Figure 7. Oil Molecules Adsorptions on Hair Blocks (Bundles)

Stage 2: Plastic Medium Mixed Flow Biotower (MFB)

In this research, a mixed flow biotower (MFB) was designed and developed, with significant hypothetical differences from conventional designs that lie in its filter medium design characteristics and media arrangements. As shown in figure 2, the major components of the MFB consists of 1) circular tower for filter medium storage, 2) hydraulic nozzle distributor equipped with high pressure hydraulic pump, and 3) filter medium consisting of hollow perforated plastic tubes arranged in alternating cross and vertical parallel manners. The first layer of the filter is made up of $40 \mathrm{~mm}$ diameter spherical plastic balls (figure 8) to achieve better uniformity of water distribution for the following layer of plastic tube medium. The hollow tubular structure of the filter medium enables the inner surface area of the hollow tubes to be used, and thus providing higher specific surface area. Additionally, the alternating vertical and cross flows could raise the void spaces to increase the biological growth for wastewater treatment. The details of specific surface area and void ratio for filter fill or selected media are shown in table 1. 


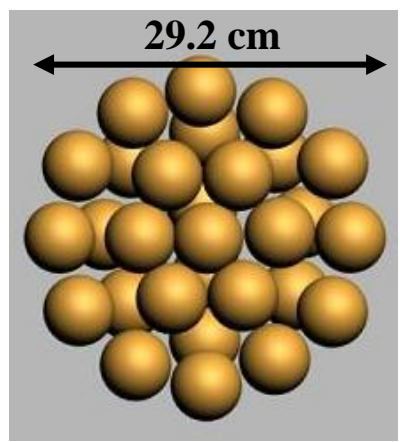

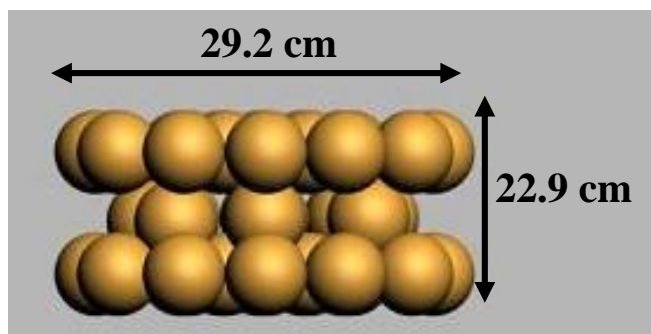

(b)

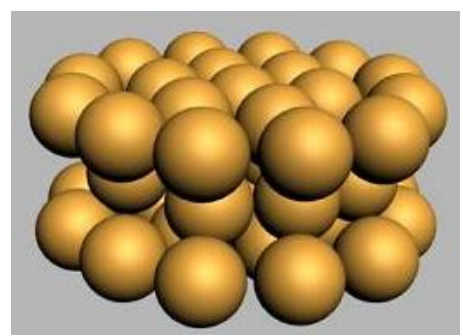

(c)

(a)

Figure 8. Spherical Balls Layer: a) Top, b) Side, and c) Perspective Views

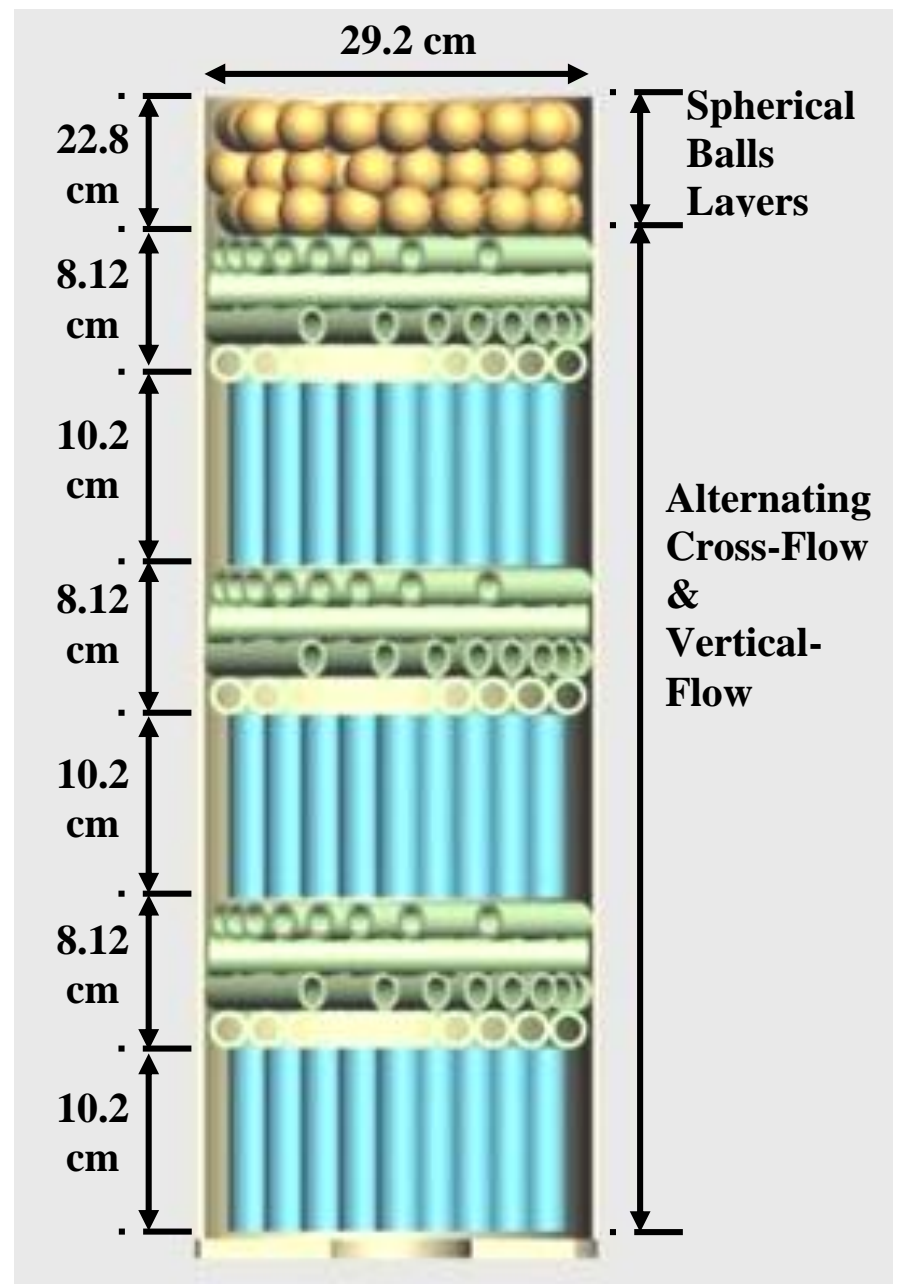

Figure 9. Biotower (Longitudinal View)

The filter medium which consists of high density polyethylene (HDPE) tubes measured $24.13 \mathrm{~mm}$ on outer diameter and $21.59 \mathrm{~mm}$ on inner diameter are alternatively placed in a plastic circular basin of $292.1 \mathrm{~mm}$ in diameter and $777.24 \mathrm{~mm}$ in height (figure 9). As shown in figure 10, the cross flow perforated tubes are arranged in four sublayers at $45^{\circ}$ between each other to enhance oxygen transfer and wetting rates. The perforated holes in cross-flow media layer tubes are approximately $7.62 \mathrm{~mm}$ in diameter at approximately $65 \mathrm{~mm}$ apart on top and bottom of the tubes. For the vertical flow layers (figure 11), each layer consists of 121 units of $101.60 \mathrm{~mm}$ vertical tubes.

Table 1. Specific Surface Area versus Void Space Percentage

\begin{tabular}{|l|l|}
\hline Volume & $52040000 \mathrm{~mm}^{3}\left(1.84 \mathrm{ft}^{3}\right)$ \\
\hline Specific Surface Area & $0.189 \mathrm{~mm}^{2} / \mathrm{mm}^{3}\left(57.50 \mathrm{ft}^{2} / \mathrm{ft}^{3}\right)$ \\
\hline Void Space & $90.60 \%$ \\
\hline
\end{tabular}



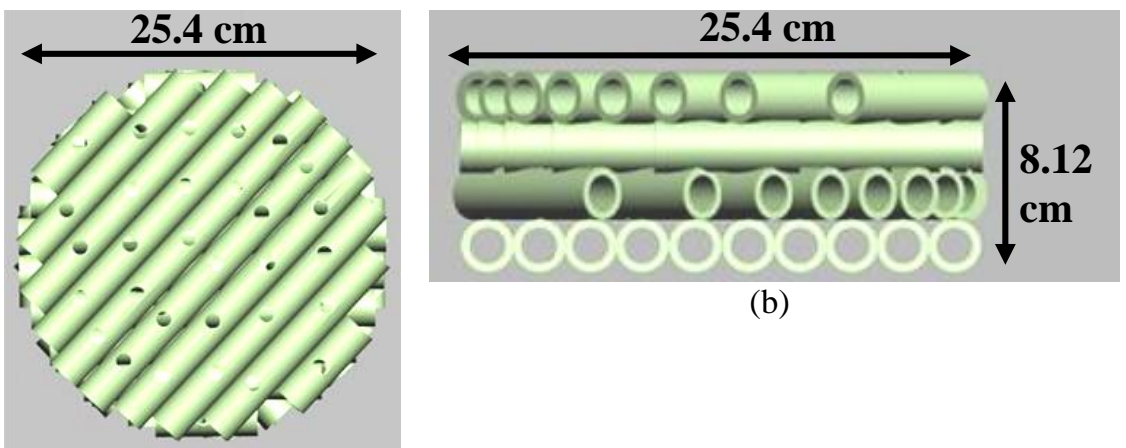

(b)

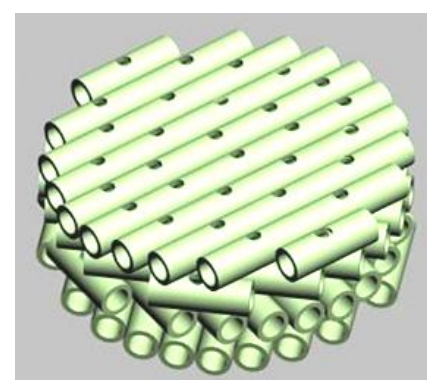

(c)

(a)

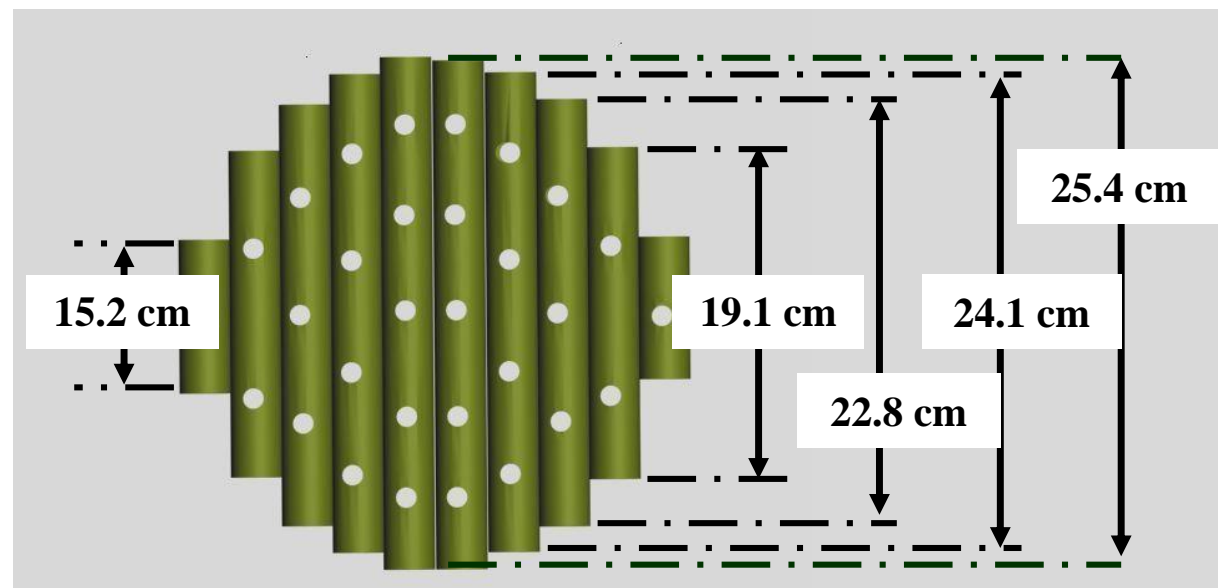

(d)

Figure 10. Cross-Flow Media: a) Top, b) Side, c) Perspective Views, and d) Tubes Dimensions

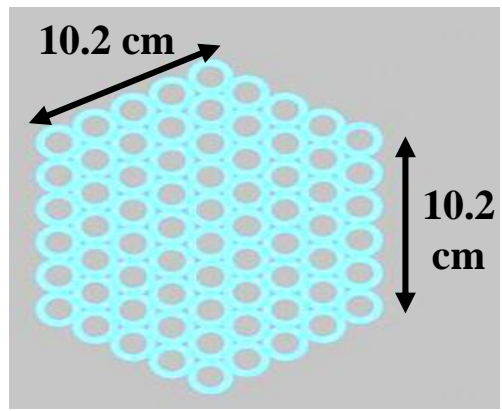

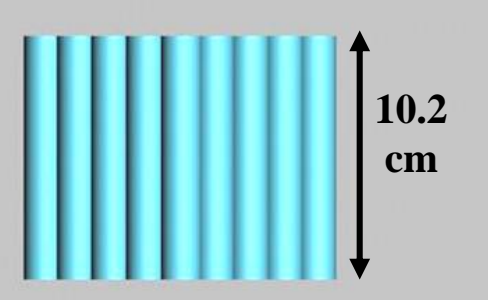

(b)

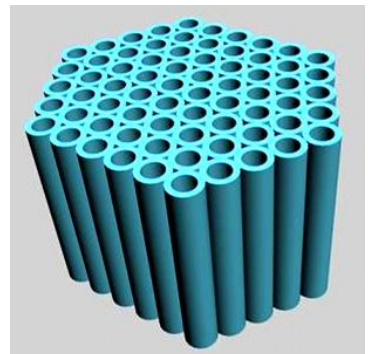

(c)

(a)

Figure 11. Vertical-Flow Media: a) Top, b) Side, and c) Perspective Views

This system is equipped with a fixed nozzle distributor controlled by a valve to permit a desired flow rate at approximately 185 liters/day (L/day) (figure 12). Flow is applied to the biotower through a hydraulic pump before being distributed by the nozzle. Because of the hydraulic gradient factor, a 6-metre pressure head hydraulic pump is selected for this purpose to provide uniform distribution of wastewater on top of MFB. The under drain collects the filtrate and solids, and serves as a source of air for the microorganisms to maintain aerobic conditions in the filter. Sufficient air is being provided to the filter medium by natural draft and wind forces through numerous ventilation ports located at the bottom of the filter. Effluents from the filter are channeled to a clarifier whereby solid particles would be settled out before overflowing to the Pistia Stratiotes-based FSW wetland system.

\section{Stage 3: Pistia Stratiotes-Based Free Surface Water Wetland System (FSW)}

The FSW wetland system consists of a plastic basin with approximately 250 liters in volume (length $=1220 \mathrm{~mm}$, width $=910 \mathrm{~mm}$, and depth $=230 \mathrm{~mm}$ ) (figure 13). The basin is partitioned into four compartments to enhance the uniformity of flow throughout the basin and two holes are provided for influents from MFB and final effluents. Operational parameters such as surface overflow rate (SOR), detention time (DT), and horizontal velocity $\left(\mathrm{V}_{\mathrm{h}}\right)$ are shown in table 2 . 


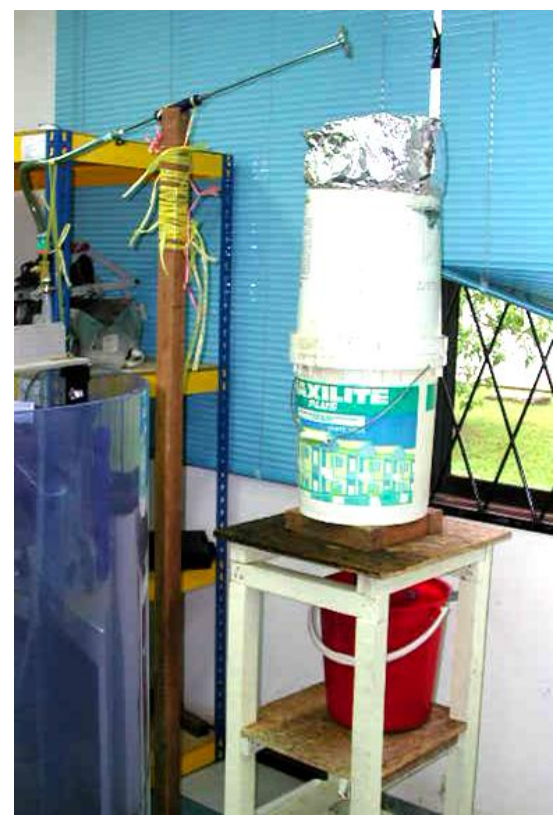

Figure 12. Setup of MFB
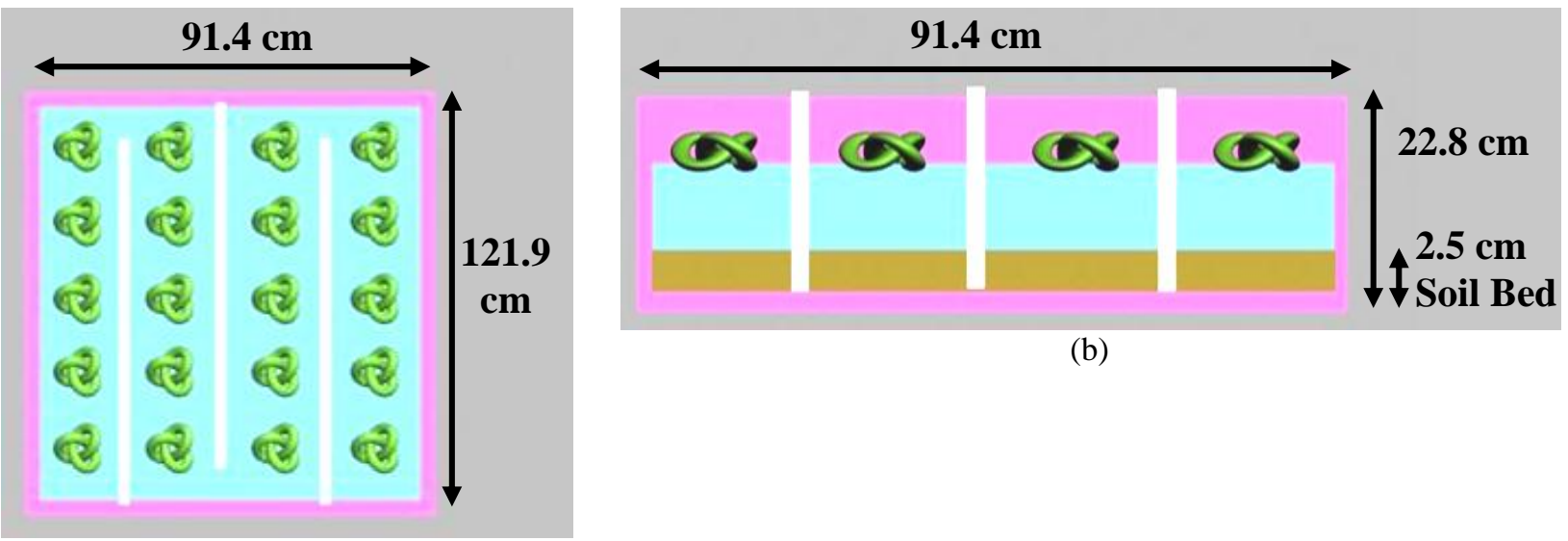

(b)

(a)

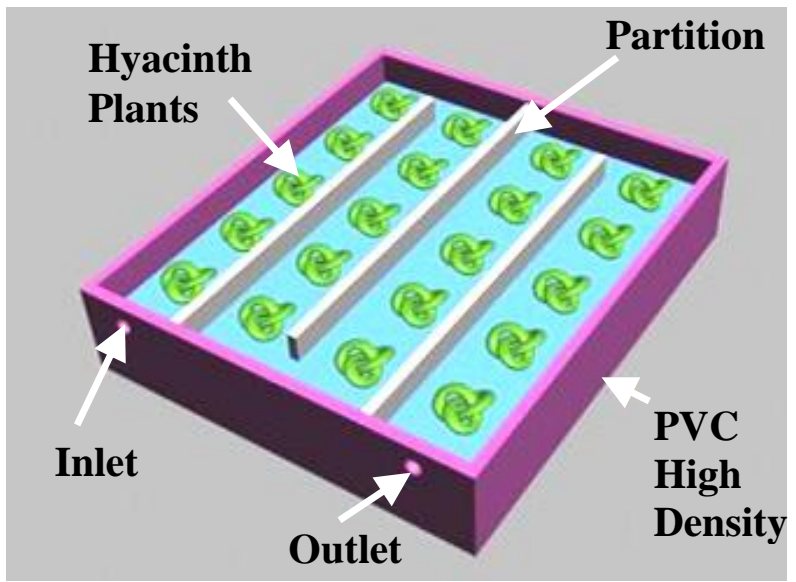

(c)

Figure 13. FWS Hyacinth-Based System: a) Top; b) Cross Section; and c) Perspective Views

Table 2 Pistia Stratiotes-Based System: SOR, DT, $\mathbf{V}_{\mathbf{h}}$

\begin{tabular}{|l|l|}
\hline Surface Overflow Rate, SOR & 166 liters/day.m ${ }^{2}$ \\
\hline Detention Time, DT & 24 hours $(1.0$ day $)$ \\
\hline Horizontal Velocity, $\mathrm{V}_{\mathrm{h}}$ & $5.15\left(10^{-2}\right) \mathrm{m} / \mathrm{hr}$ \\
\hline
\end{tabular}




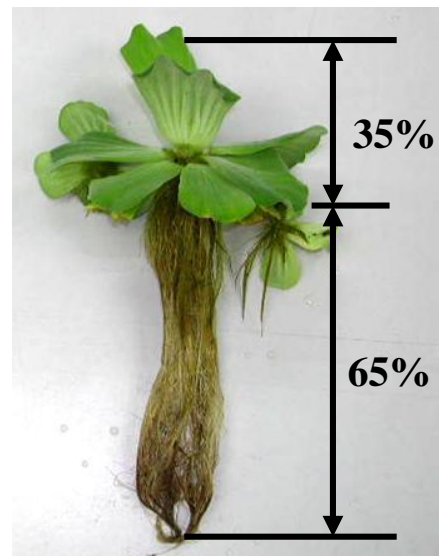

Figure 14. Leave-To-Root Ratio of Pistia Stratiotes

In this research, the Pistia Stratiotes-based FSW wetland system is filled with a type of floating tropical Water Lettuce called "Pistia Stratiotes" (figure 14). Pistia Stratiotes is characterized by numerous suspended roots of over one foot long $(>300 \mathrm{~mm})$. The above-water portion consisting of leaves are traditionally used as animal feeds frequently practiced by local farmers in the tropics [19]. Pistia Stratiotes is a free-floating aquatic plant commonly used as an ornamental plant in water gardens. This tropical water lettuce produces attractive rosettes of bright green, wedged shaped, overlapping, deeply veined velvety leaves that grow up to 10 inches (254 mm) long and 4 inches $(101.6 \mathrm{~mm})$ wide. This species of hyacinth grows well outdoors all year-round in the tropics with water $\mathrm{pH}$ between 6.2 and 7.2 [19], [22]. The Pistia Stratiotes, because of its floating capabilities, is believed to have filtration capability for ponds with high nitrogen and phosphate levels. This type of water lettuce grows vegetatively by production of daughter plants that allows intertwining of the plants, thereby forming large contiguous mats of floating vegetation [19], [22]. These mats are one of the most important growth characteristics contributing to the removal of nutrients from wastewaters. Details on system design outlining the dimensions of settling basin and water lettucebased system are summarized in table 3 .

Table 3 Summary of Design Dimensions of the 3-Stage Treatment System

\begin{tabular}{|c|c|c|c|c|c|}
\hline \multicolumn{6}{|c|}{ Spiral-Framed Human Hair-Based Filter (HBF) } \\
\hline \multirow[t]{4}{*}{ a) } & Storage Tank & Flow Rate & $=$ & 0.037 & $\mathrm{~L} / \mathrm{s}$ \\
\hline & & Diameter & $=$ & 750 & $\mathrm{~mm}$ \\
\hline & & Height & $=$ & 460 & $\mathrm{~mm}$ \\
\hline & & Volume & $=$ & 20.32 & liters \\
\hline \multirow[t]{2}{*}{ b) } & Hair Blocks & Wire Mesh Caging Thickness & $=$ & 25 & $\mathrm{~mm}$ \\
\hline & & Total Hair Weight Used & $=$ & 5.2 & $\mathrm{~kg}$ \\
\hline \multirow[t]{4}{*}{ c) } & Spiral Plane & Aluminium Plate Thickness & $=$ & 1 & $\mathrm{~mm}$ \\
\hline & & Gap Between Plate & $=$ & 11 & $\mathrm{~mm}$ \\
\hline & & Gap Between Hair Blocks & $=$ & 6 & $\mathrm{~mm}$ \\
\hline & & Spiral Rotation Radian & $=$ & $\theta$ & $\mathrm{rad}$ \\
\hline \multirow[t]{4}{*}{ d) } & Baffle Zone & Zone Distance & $=$ & 50 & $\mathrm{~mm}$ \\
\hline & & Gap Between Baffle Plate \& Collection Weir & $=$ & 15 & $\mathrm{~mm}$ \\
\hline & & Collection Weir & $=$ & 35 & $\mathrm{~mm}$ \\
\hline & & Gap Between Plate \& Bottom of Tank & $=$ & 95 & $\mathrm{~mm}$ \\
\hline \multirow[t]{2}{*}{ e) } & Core Well & Diameter & $=$ & 150 & $\mathrm{~mm}$ \\
\hline & & Core Pipe Diameter & $=$ & 18 & $\mathrm{~mm}$ \\
\hline \multicolumn{6}{|c|}{ Mixed Flow Biotower (MFB) } \\
\hline \multirow[t]{4}{*}{ a) } & Storage Basin & Flow Rate & $=$ & 185 & L/day \\
\hline & & Diameter & $=$ & 292 & $\mathrm{~mm}$ \\
\hline & & Height & $=$ & 777 & $\mathrm{~mm}$ \\
\hline & & Volume & $=$ & 52.1 & liters \\
\hline \multirow[t]{2}{*}{ b) } & Spherical Balls & Diameter & $=$ & 40 & $\mathrm{~mm}$ \\
\hline & & Number of Unit & $=$ & 85 & \\
\hline \multirow[t]{8}{*}{ c) } & Cylindrical Tubes & & & & \\
\hline & i) $\quad$ Cro & flow & & & \\
\hline & & olid Surface & & & \\
\hline & & Tube Internal Diameter & $=$ & 21.5 & $\mathrm{~mm}$ \\
\hline & & Tube External Diameter & $=$ & 24.1 & $\mathrm{~mm}$ \\
\hline & & Length of Tube & $=$ & $152.4-254$ & $\mathrm{~mm}$ \\
\hline & & Number of Sub-Layer@Layer & $=$ & 4@3 & \\
\hline & & ole & & & \\
\hline
\end{tabular}




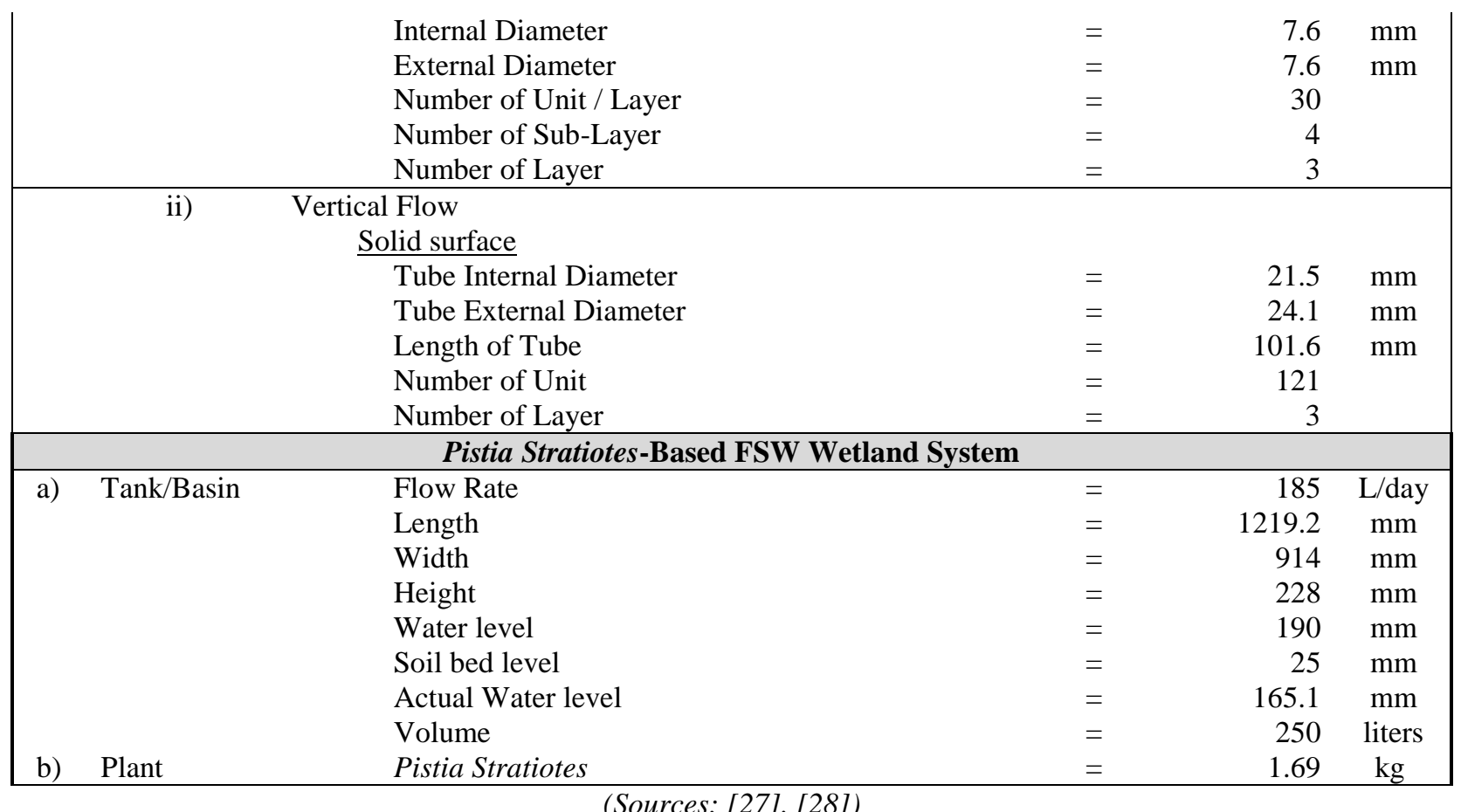

\section{CONCLUSIONS}

A micro-scale 3-stage treatment system for domestic wastewaters was recently developed and its performance was evaluated for removal of emulsified and free oils, organics and nutrients from wastewaters. The three key components of the system include 1) HBF, 2) MFB and 3) FSW wetland. Positive data gathered during literature search, coupled with revolutionized novel design and operational criteria had led to the conclusions that the current micro-scale 3stage treatment system for domestic wastewater could have an immense potential of application. For HBF, the hypothetical superior installation technique of hair blocks on both sides of the spiralling flow path could promote optimum adsorption of O\&G by taking advantage of the principles that flow movement in spiral plane that would result in rapid and continual turning and reflection of flow. This promotes more adsorption occurrences between hair blocks and oil drops. Collisions between the hair blocks and oil drops would significantly be raised as the contact surface area increases. Additionally, human hair is believed to be an excellent adsorptive material for O\&G. One of the novel design criteria of MFB is the provision of alternated cross and vertical flows to ensure an even flow (trickle down) of wastewater in the filter, in addition to increasing total media surface area and void space in the system. Flow is applied to MFB through a hydraulic pump before being distributed by a fixed nozzle distributor controlled by a valve to permit a desired flow rate at approximately 185 liters/day (L/day). The under drain collects the filtrate and solids, that also serves as a source of air for the microorganisms to maintain aerobic conditions in the filter. Sufficient air is being provided to the filter medium by natural draft and wind forces through numerous ventilation ports located at the bottom of the filter. Effluents from the filter are channelled to a clarifier whereby solid particles would be settled out before overflowing to the Pistia Stratiotes-based FSW wetland system. For the FSW wetland system, because of the floating capabilities of Pistia Stratiotes, it is believed to have significant filtration capability for wastewaters with relatively high levels of nitrogen and phosphate. This type of water lettuce grows vegetatively by production of daughter plants that allows intertwining of the plants, thereby forming large contiguous mats of floating vegetation. These mats are one of the most important growth characteristics contributing to the removal of nutrients from wastewaters.

\section{ACKNOWLEDGEMENT}

The authors convey their appreciation to the Graduate Studies and Research Support Division and the financial support of the University of Malaysia Sarawak.

\section{REFERENCES}

[1] S.H. Abdullatif, P.L. Law, H.H. Lau, A. Baharun. (2008). "Optimum coalescence plate arc length for removal of oil droplets from wastewaters." Journal of Engineering Science \& Technology, 2(3), pp. 247-259. Available: http://jestec.taylors.edu.my/Vol\%202\%20Issue\%203\%20December\%2007/247-259\%20Almarouf.pdf

[2] G. J. Alaerts, M. R. Mahbubar, P. Kelderman. (1996). "Performance analysis of a fullscale duckweed covered sewage lagoon." Water Resources Development, 30(4), pp. 843-852. Available: doi:10.1016/0043-1354(95)00234-0 
[3] J. Arianne, "Can natural products pick up oil as effectively as polypropylene." Selah Science Project Grade 6 and 7 of 2002, 2006. Available: http://www.Selah.K12.Wa.Us/SOAR/Sciproj2002/Ariannej.Html -->

[4] B. Barraza, P. Sanchez, "What makes the best oil spill cleaner: hair, cotton, or feathers," California State Science Fair 2001 Project Summary, 2001. Available: http://www.usc.edu/CSSF/History/2001/Projects/J0801.pdf

[5] Brentwood Accupac Cross Flow Media, Brentwood Industries, 2004. Available: http://www.brentwoodprocess.com/crossflow.html

[6] H. Brix, H Schierup. (1989). "The use of aquatic macrophytes in water pollution control," Ambio, 18(2), pp. 100-107. Available: http://mit.biology.au.dk/ biohbn/hansbrix/pdf_files/Ambio_1989_100-107.pdf

[7] Los Angeles Times, Common Dreams News Center , 2001. Available: http://www.commondreams.org/headlines01/1105-04.htm

[8] R.A. Corbitt, Standard Handbook of Environmental Engineering, Mc-Graw Hill Publication, New York, United States of America (USA), 1989.

[9] Malaysia Environmental Quality Report 2005, Department of Environmental, Department of Ministry Of Science, Technology and Environmental, MOSTE, 2005

[10] A. Gray, "Logarithmic spirals," Modern Differential Geometry of Curves and Surfaces with Mathematica, 2nd Ed. Boca Raton, FL: CRC Press, 1997, pp. 40-42.

[11] A. Gray, "Logarithmic spirals." Modern Differential Geometry of Curves and Surfaces with Mathematica, 2nd Ed. Boca Raton, FL: CRC Press, 1997, pp. 90-92.

[12] R. Haberl, R. Perfler, H. Mayer. (1995). “Constructed wetlands in Europe,” Water, Science and Technology, 32 (3), pp. 305-315. Available: http://www.iwaponline.com/wst/03203/0305/032030305.pdf

[13] S.A. Haidar, "A Phase separator with inclined parallel arc coalescing plates (ipacp) for removal of physically emulsified and free oils from wastewater." Ph.D. dissertation, Department of Civil Engineering, Faculty of Engineering, Universiti Malaysia Sarawak (UNIMAS), Malaysia, 2008. Available: http://cais-mill.unimas.my/search

[14] M.J. Hammer, M.J.J. Hammer, Water And Wastewater Technology, Pearson Prentice-Hall Inc., Upper Saddle River, New Jersey, United States of America, 2004.

[15] J.R. Hauser, "Use of wastewater aquatic treatment system for ammonia control and effluent polishing." Research Journal of the Water Pollution Control Federation, 56(3), 1984, pp. 219-225.

[16] S.P. Howard, D.R. Rowe, G. Tchobangolous, "Environmental engineering," Civil Engineering Series, McGraw-Hill International Editions, Singapore, 1985

[17] W. Kirchhof (1988). "Wastewater treatment in low cost bamboo biotowers and pond system," in Proceedings of the International Bamboo Workshop held in Cochin, India. Available: http://www.inbar.int/publication/txt/INBAR PR 02.htm

[18] S.S. Krishnan, A. Cancilla, R.E. Jervis. (1988). Wastewater treatment for heavy metal toxins using plant and hair as adsorbents. Pubmed, 68, pp. 267-73. Available: http://www.ncbi.nlm.nih.gov/sites/entrez

[19] P. Kumar, R.J. Garde. (1989). Potentials of Water Lettuce for Sewage Treatment, Research Journal of the Water Pollution Control Federation, 61 (11/12), pp 1702-1706.

[20] P.L. Law, L.H. Ngu, K.K. Wong, A.A. Rahman. (2006). Development and performance tests of a separator for removal of physically emulsified and free oils from wastewaters." Journal of the Institution of Engineers, Malaysia (IEM), 67(2), pp. 10-19. Available: http://www.iem.org.my/wapi/mctweb.dll/getObject?mid=IEMWEB-MAIN2\&ObjID=225

[21] L. Mandi. (1994). Marrakesh wastewater purification experiment using vascular aquatic plants eichhornia crassipes and lemna gibba. Water, Science \& Technology, 29(4), pp. 283-287.

[22] R. Mars, "Greywater Treatment with Macrophytes," Greywater Reuse Systems. Midland Business Centre, Washington,2004. Available: http://www.greywaterreuse.com.au/index.php/Greywater-Reuse-Systems/Greywater-Treatment-with-Macrophytes.html

[23] E. J. Middlebrooks. (1995). Upgrading pond effluents: an overview. Water, Science \& Technology, 31(12), pp. 353-368. Available: http://www.iwaponline.com/wst/03112/0353/031120353.pdf

[24] National Research Council (NRC), "Using oil pollution dispersants on the sea." National Academy Press, Washington, D.C,1989. Available: http://www.nap.edu/openbook.php?record_id=736\&page=R2

[25] L.H. Ngu. "Development and optimization of a circular phase separator with dual angle coalescence plates for removal of suspended solids, free and physically emulsified oils from wastewaters." Ph.D. dissertation, Department of Civil Engineering, Faculty of Engineering, Universiti Malaysia Sarawak (UNIMAS), 2008. Available:http://cais-mill.unimas.my/search

[26] L.H. Ngu, "Development \& performance tests of a separator for removal of physically emulsified oils from wastewater." M.Eng Thesis, Department of Civil Engineering, Faculty of Engineering, Universiti Malaysia Sarawak (UNIMAS), Malaysia, 2004. Available: http://caismill.unimas.my/search

[27] Y.W. Oon, "Development and performance evaluation of a 3-stage treatment system for domestic wastewater." M.Eng Thesis, Department of Civil Engineering, Faculty of Engineering, Universiti Malaysia Sarawak (UNIMAS), Malaysia, 2008. Available: http://caismill.unimas.my/search

[28] Y.W. Oon, "A micro-scale wastewater treatment system for domestic effluents." B.Eng Thesis, Department of Civil Engineering, Faculty of Engineering, Universiti Malaysia Sarawak (UNIMAS), Malaysia, 2005. Available:http://cais-mill.unimas.my/search

[29] G. Oron. (1990). "Economic considerations in wastewater treatment with duckweed for effluent and nitrogen renovation." Research Journal $W P C F, 62(5)$, pp. 692-696. Available: http://www.jstor.org/pss/25043900

[30] T.D. Reynolds, Unit Operations and Processes in Environmental Engineering, Boston, Massachusetts, United States of America (USA), 1982.

[31] J.F. Tamar, "Toil with oil," California State Science Fair 2004 Project Summary. 2004. Available: http://www.usc.edu/CSSF/History/2004/Projects/J08.pdf

[32] G. Tchobangoglous, F.L. Burton, Wastewater Engineering: Treatment, Disposal, and Reuse, Third Edition. Metcalf \& Eddy, Inc., USA, 1991.

[33] P. Tensie, "Oil absorbency of polypropylene pads vs. natural products." Selah Science Project Grade 6 and 7, 2006. Available:http://www.selah.k12.wa.us/soar/sciproj2006/TensieP.html

[34] Wastewater technology fact sheet trickling filters, EPA 832-F-00-014, United States Environmental Protection Agency (USEPA), Office of Water, Washington, D.C.,2000. Available: http://www.epa.gov/owm/mtb/trickling_filter.pdf

[35] Wastewater technology fact sheet trickling filter nitrification, EPA 832-F-00-015, United States Environmental Protection Agency (USEPA), Office of Water, Washington, D.C., 2000. Available: http://www.epa.gov/OWM/mtb/trickling filt nitrification.pdf 